\title{
Are Gestures of One Culture the Same as Those of the Another One? In the Search of Cross-Cultural Differences in Nonverbal Behaviour from the Perspective of Cognitive Linguistics
}

\begin{abstract}
From all the examples of nonverbal behaviour it has been scientifically proved that gestures reflect human thoughts and mental operations. Gestures project meanings that are stored in image schemas. Those mental representations are shaped by culturally determined experience. The aim of this article was to delve into the issue of the cross-cultural differences in nonverbal behaviour with the particular focus on gestures from the point of view of cognitive linguistics. It was also of my interest to identify and categorise gestures as regards their universal and/or culture specific nature and create a background for possible further research.
\end{abstract}

\section{INTRODUCTION}

"Those countries which do the best in the world - the ones that are safe and prosperous - have a coherent sense of their own culture" (Paxman 1999). Paxman who refers to Great Britain is obviusly true, however it is not only power and prosperity that unite nations. Each culture is unique due to its norms, traditions, history and the language that reveals mentality of the representants and adds to the shaping of it. My particular interest focuses on nonverbal behaviour. Since there have only been a scarce number of scientific trials to explain the culture-specific nonverbal behaviour (being an integral part with a language - McNeill 1992) it is the aim of this article to approach this field of linguistic studies. By means of this article I shall develop the issue of the source of the cross-cultural differences in nonverbal behaviour. Also, I shall analyse the actual notions in a language, accompanied by gestures, which both are universal and those that significantly differ each other between the languages. 


\section{WHY ARE GESTURES IN THE SPHERE OF INTEREST?}

Among such nonverbal channels as mimicry, proxemics (distance and space), haptics (touch) and personal appearance gestures "are the most semantic tools of communication" as Aneta Zalazińska (2001) states. As early as in 1972 Ekman and Friesen (in Furnham 1999) noticed the functional nature of gestures that resulted in their famous classification of: emblems, illustrators, regulators, adaptators and manifestators.

Gestures seem to be the least accidental or vague. They are considered by the cognitivists to reflect the real meaning and relations of human thoughts generated in mental representations. As Jolanta Antas (1996) (in Zalazińska 2001) pinpoints, gestures are prior tools of communication to the verbal channel. That is that they are the closest processors of semantic meaning to humans and such inclination towards movement during the interaction is natural (it comes from the human inclination to do so). Therefore it seems highly reasonable to analyse communication in terms of its verbal as well as nonverbal transmitters of speech. David McNeill (1992) assumes gestures to constitute the integral system with the verbal language. He goes even further in claiming that gestures reflect human thoughts as efficiently as the terms do. Cognitivists feel free to express similar views, since they base their viewpoints on the idea of the Lakoffian "embodied mind".

\section{“THE EMBODIED MIND" \\ - GESTURES AS TOOLS AND REALIZATIONS OF MENTAL OPERATIONS}

Jolanta Antas (2006) (in Tabakowska 2006) provides the following explanation of the origins and existence of human gestures.

... what actually exists behind the gestures are not the drawings of the objects or their copies, but real mental images. Gestures are the drawings of those mental images (...) gestures do not illustrate the meanings of words but they represent iconic thought gestalts that stand behind the words.

Gestures uncover one's thoughts and even more importantly, this process is subconscious. According to Zalazińska, a Polish pioneer in the cognitive linguistic approach to nonverbal behaviour, abstract ideas are represented by gestures carrying the prototypical meanings of them. For instance, the verb "to have" shall always be illustated by the gesture displaying its possesive aspect, although as the dictionary explanations point out the term expresses also other related meanings.

"Thought representations are determined by our existence. The experience is reflected in the mental structures (Zalazińska 2000)." Mind is being 
developed throughout the thinking process, which takes place thanks to the cognitive representations (terms and the coexisting gestures are stored in schemas). Terms and gestures are created in the course of experience. Gestures accompany the terms. The meaning of a given idea is being transmitted by two channels: verbal and nonverbal. At first glance it is happening simultaneously, however it has been proved that the nonverbal message slightly exceeds the verbal one (what may confirm the thesis of the gestures being the primary meaning transmitters to humans). We may also observe on an every day basis that this dual channelling happens to be more or less separated during the interaction, e.g. when one forgets a verbal equivalent of a given term and he/she compensates it by using gestures and then the uttered name of it appears later or not.

Gestures are the carriers of meaning (that differs contextually in cultures).

...the real difference between the languages does not depend on what may or may not be expressed by means of them but what a language user has to or does not have to express in them. (Jakobson 1959 in Dąbrowska / Kubiński 2003).

\section{WHAT GESTURES ARE CULTURALLY DETERMINED?}

Provided there existed a perfect interpreter from language A to language $B$ who knows every possible difference between both languages including their verbal and nonverbal behaviour. Would he/she find B nonverbal equivalents to A gestures? If yes, what notions in the communication event would they concern? Surely, the nonverbal interpreting would apply to standardised gesturing, such as in case of emblems or illustrators (Ekman / Friesen 1972 in Furnham 1999), as there are scientific proves for their cultural difference. However, the question is how many British gestures (apart from those clearly genetically-, universally- and culturally-bound) exist as culturally determined and what exactly they are?

Janina Parafiniuk-Soińska (2003) claims that the behaviour of a human being is influenced both by current external stimuli and internal cognitive structures.

The production and understanding of one's interlocutor's nonverbal behaviour is culturally determined and deeply rooted the human cognitive structures. Romney (1995) explicitly regards cognitive representations as being common for the individuals within a given culture.

Due to the - in Piagetan terms - assimilation, accomodation and equilibration processes (Williams / Burden 1997) taking place in varied worldwide environments language users acquire different knowledge that is shaped by the given culture consisted of norms, standards, beliefs, tradi- 
tions, etc. Once acquired experience is stored in mental representations that enable the recognition and categorization of the sensory data, an external input, (Maruszewski 2001) as well as the meaningful interaction among the representants of one's culture. The interaction becomes meaningful due to the shared (intersubjective) symbols among the members of a given culture (Tomasello 1999). Those symbols, as Tomasello calls them, refer both to the verbal and nonverbal behaviour.

The matter is however what symbols may be worldwide equally understood, because of their universality and which of them appear purely in some culture specific contexts. The figure below includes the scientifically proved nature of gestures on the scale ranging from the universal to culture determined ones.

Universal

Culture specific

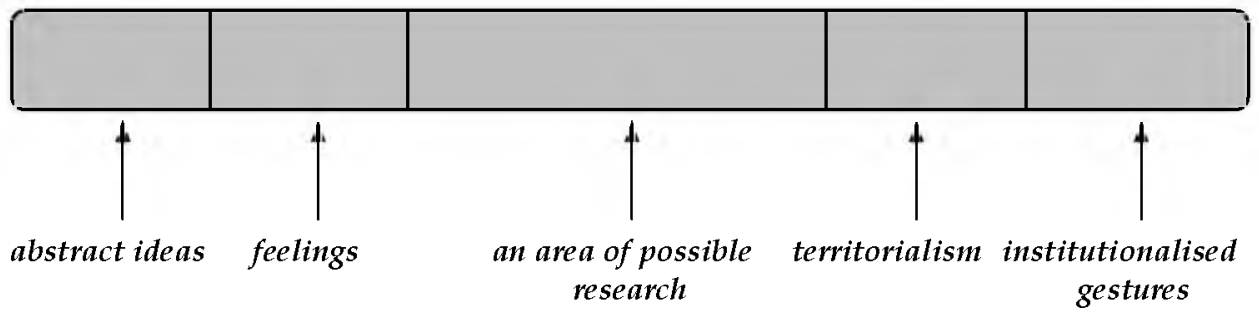

Figure 1. Culture dependence of gestures, facial expressions and proxemics

According to Zalazińska's research, (Zalazińska 2000) such abstract terms as: 'to have,' 'not to have', 'lack of sth', 'nothing', 'something', 'all', 'to need', 'to want' have gestural equivalents that are rather common for all humans, who share the same physical experience. Every above abstract notion seems to relate to the basic activity that one has come across in their life regardless of the national history, political system, beliefs, etc. Such activity may include possesion of anything more or less valuable, as well as one's positive attitudes or ambitions regarding the above. Those ideas are familiar to both primitive tribes and civilised countries, even if unrealized among the representants of the two. Therefore due to their similar nature across the globe they are, as Zalazińska (2000) concludes, mentally categorized and located in schemas on the basis of their prototypical meanings. That in turn results in common (universal) gestural pattern across cultures for the particular notion. The place on the universalculture specific scale of the abovementioned behaviour seems to be undoubted. However, that does not mean that there is no entry to the 'culture specific' category for other 'abstract terms' originating from the cross-cultural experience. All what is needed is some extra investigation in this particular field. 
Further on the scale what is placed is the nonverbal behaviour present at times of the feelings expression. The origin of those nonverbal elements seems to be quite ambiguous, since a lot of renowned antropologists and psychologists have different opinions in this matter. Margaret Mead finds them culturally specific, while Paul Ekman following Darwin's stand considers them universal (Zalazińska 2000). Ekman (1962) (in Prinz 2003) conducted a research where he proved that such feelings as: anger, disgust, fear, joy, sadness, surprise and most probably contempt are being universally recognized. There seems to be, however, a possibility that the universality of the above ends in their common understanding. Their appearance or intensity may be contextually differentiated among cultures. For instance, British people do not display their negative emotions - it is politically incorrect - as frequently as Poles do. Polish people tend to complain when asked how they do, unlike the British who most often express optimistic attitudes. Obviously, that depends on the context and interlocutors, however statistically the citizens of England significantly differ from Poles in the frequency and intensity of the displayed emotions.

Territorialism refers to the term proxemics, which was widely investigated by Edward T. Hall. Hall (1990) proved that there exist specified spaces, though in not very stiff ranges, that signify distance preferences depending on social situations. Those spaces include intimate, personal, social and public zones. The ranges seem to suggest that spaces may differ not only according to the individual preferences but also they might be standard as far as particular cultures are concerned.

Gestures that are rather informally standardised and thus culturally dependendent include all types of emblems. (Ekman / Friesen 1972 in Furnham 1999) Emblems are autonomous and they can be used interchangeably with their verbal equivalents without any alteration in meaning of the initial idea. For example, the fist with the index and middle fingers raised and the palm directed towards the speaker himself in Great Britain accounts for 'Get lost' while in Poland it means nothing significant. The same gesture signifies 'two' in the USA. Poles start counting on fingers from the thumb while Anglo-Saxon countries do the same from the index finger (Pease 2007). To the culture specific gestures also belong illustrators that add to the meaning expressed vocally. According to Furnham (1999) the Anglo-Saxon culture members gesture scarcely. This happens contrary to Poles who seem to gesture quite frequently.

\section{CONCLUSION}

Cross-cultural differences in nonverbal behaviour are fairly obvious. It is enough to take into consideration the tenets of cognitivism and constructivism that stress the importance of creative (not automatic) mind as well as 
experience in language processing. The experience varies culturally due to the differences in mentality that seems to be composed of such factors as history, geography, politics, values, language, etc. Many scientists prove that schemas in mind are universal: based on the prototypical copies of designates. What in fact differs among cultures are the cognition and interpretation of the reality resulting in the variations in verbal and nonverbal behaviour. The aim of the article was to analyze the elements of nonverbal behaviour with the main focus on culture specific gestures expressing different notions, in order to provide a background for some new research in the field. Not all of the culture dependent gestures have been investigated yet as well as their origins as far as mind is concerned. Therefore apart from the institutionalised gestures the researcher aspires to find and prove scientifically the existence of other gestural realizations of thought that shall differ crossculturally, especially in British and Polish contexts.

\section{REFERENCES}

Dąbrowska, E. / Kubinski, W., 2003. Akwizycja języka w świetle językoznawstwa kognitywnego. Kraków: Universitas.

Furnham, A., 1999. Body language. Warszawa: Petit.

Hall, E., 1990. The silent language. New York: Anchor Books.

Marcjanik, M., 2007. Grzeczność w komunikacji językowej. Warszawa: Wydawnictwo Naukowe PWN

Maruszewski, T., 2001. Psychologia poznania. Gdańsk: Gdańskie Wydawnictwo Psychologiczne.

McNeill, D., 1992. Hand \& Mind. Chicago: University of Chicago Press.

Parafiniuk-Soińska, J., 2003. O międzyludzkiej komunikacji. Szczecin: Wydawnictwo OR TWP.

Paxman, J., 1999. The English. The portrait of a people. London: Penguin Books.

Pease, A. \& B., 2007. Mowa ciała. Poznań: Dom Wydawniczy Rebis.

Prinz, J., 2003. Emotions Embodied. www.unc.edu/ prinz/PrinzEmotionsEmbodied

Rusinek, M. / Załazińska, A., 2005. Retoryka podręczna, czyli jak wnikliwie słuchać i przekonująco mówić. Kraków: Wydawnictwo Znak.

Tabakowska, E., 2006. Ikoniczność znaku: stowo - przedmiot-obraz-gest. Kraków: Universitas.

Tomasello, M., 2002. Kulturowe źódta ludzkiego poznania. Warszawa: Państwowy Instytut Wydawniczy.

Williams, M. / Burden, R., 1997. Psychology for Language Teachers: A social Constructivist approach. Cambridge: Cambridge University Press.

Załazińska, A., 2001. Schematy myśsli wyrażane w gestach. Kraków: Universitas. 